\title{
Attitude of Parents towards Hearing Impaired Children
}

\author{
Dr. Y. Pavan Kumar ${ }^{1}$, V. Sai Sree Lalitha ${ }^{2}$ \\ Principal, K. M. M. College, Tirupati, Chittoor (District), Andhra Pradesh, India, Pin -517 102. \\ Asst. Professor, Sri Prakash College, Ellamanchili, Visakapatnam (District), Andhra Pradesh, India, Pin- 531
} 055

\begin{abstract}
In the present study an attempt has been made to investigate the attitude of parents of hearing impaired children and parents of normal children towards their children. Parental attitude scale was developed by Schafer and Bell (1958) based on the original inventory designed by Shoben was administered on 120 parents out of which 30 fathers and 30 mothers has children with hearing impaired and 30 fathers and 30 mothers with normal children were in the age of 9-15 years. To find out the significance difference between two Means ' $t$ ' test was carried out
\end{abstract}

\section{Keywords: Hearing impaired children, attitude, normal children, parents, fathers and mothers}

The ears and the eyes are the gates of learning for the mankind. The ability of communication is a crucial factor to thriving, working ability and emotional well-being. Man is highly dependent on senses. From these he builds his world, learns to conceptualize and to reason. The five basic sense organs play an important role in personality of an individual. Of all the five senses, audition is perhaps the most important sense organ since it is the primary means by which we monitor or interact with the linguistic environment.

Rearing of children is a very important duty of all the families. At the same time it is probably one of the most delicate of all functions of the family. If the parents are successful in the function, it could bring the maximum satisfaction to them. It is the parents who help the child development into an adult person with their continues care, concern, love and guidance. Parents can take different attitudes towards the child.

The impact of parental attitude on growing children has been well recognized. The well adjusted and successful children usually come from homes where their parental attitude is favourable. The children who face unfavourable attitude develop behavioural problems.

The effects of parental attitude have been studied by srivastava et al. (1969). In his study he found that mothers of deaf children were more reserved, emotionally less stable, humble, suspicious, imaginative, apprehensive and tense than the mothers of normal children.

Daniel and Dibawal (1977) reported that parents of deaf children encounter tremendous difficulties in developing positive parental relationship. Wendel et al. (1980) found that deaf children are passive and less actively involved in the interactions than their hearing counterparts.

Himavalli (1989) reported that mothers and fathers have a positive attitude towards their deaf children. Kalavathi (1993) in her study revealed that parents of the normal children high positive attitude than the parents of handicapped children.

Different parental attitudes commonly seen towards the child are over affection and over protection, indulgence, over anxiety, under affection, rejection, over authority, over responsibility and others. These attitudes affects these children's' personality. Children who are over protected have difficulty in making friends and they become aggressive, selfish and boastful.

The attitudes of the parents ultimately affect only their children, whether they are normal or physically challenged. The handicapped children need special help of physical and psychological reasons. In the absence of appropriate help, they will live below the level of their potential.

\section{HYPOTHESES}

1. There would be no significant difference between the parents of hearing impaired children and parents of normal children towards their children.

2. There would be no significant difference between the fathers and mothers of hearing impaired children towards their children.

3. There would be no significant difference between the fathers and mothers of normal children towards their children.

4. There would be no significant difference between the mothers of hearing impaired children and mothers of normal children towards their children.

5. There would be no significant difference between the fathers of hearing impaired children and fathers of normal children towards their children. 
SAMPLE

\section{METHOD}

A sample consisted of 120 parents out of which 30 fathers and 30 mothers has children with hearing impairment and 30 fathers and 30 mothers has normal children were in the age of 9-15 years. The sample was selected from two educational institutions located at Ongole town.

TOOL

Parental attitude scale was developed by Schafer and Bell (1958) based on the original inventory designed by Shoben. This instrument consists of 115 items. Each item describes a specific child rearing practice generally adopted by parents. This test was administered to both the parents of hearing impaired and parents of normal children and the data were collected.

\section{ANALYSIS OF RESULTS}

The data were analyzed statistically by 't' test to find out the significance of the difference between the mean scores of the parents of hearing impaired and parents of normal children.

Table 1 shows the mean score (296.8) of parents of hearing impaired children and the mean score (315.3) of parents of normal children. Parents of normal children mean score is more than the parents hearing impaired children. It indicates that the parents of normal children are better attitude towards their children. The ' $t$ ' value (5.65) is found to be significant. Hence there is significant difference between the parents of hearing impaired and parents of normal children with regard to the attitude of their children.

Table -1

Means and Standard Deviations of Parents of Hearing Impaired and Parents of Normal children and the Results of' $t$ ' 'Test.

\begin{tabular}{|l|l|l|l|l|}
\hline \multicolumn{1}{|c|}{ Groups } & N & Mean & S.D & 't' test \\
\hline Parents of hearing impaired children & 60 & 295.9 & 11.43 & \multirow{2}{*}{$5.45^{* *}$} \\
\hline Parents of normal children & 60 & 315.3 & 21.14 & \\
\hline
\end{tabular}

** Significant at 0.01 level.

These results are consonance with the findings of Kalavathi (1993) who studied parental attitude towards their handicapped children found that parents of the normal children have high positive attitudes than the parents of handicapped children.

Table2 indicates that the mean score (295.3) of fathers of hearing impaired children and mean scores (298.4) of mothers of hearing impaired children and its difference is less (3.1). The obtained't' value (1.31) is not significant. Hence, there is no significant difference between the fathers and mothers of hearing impaired children with regard to the attitude towards their children is accepted.

Table2

Means and Standard Deviations of Fathers and Mothers of Hearing Impaired Children and the Result of't' Test.

\begin{tabular}{|l|l|l|l|l|}
\hline \multicolumn{1}{|c|}{ Groups (Hearing Impaired) } & N & Mean & S.D & 't' test \\
\hline Fathers & 30 & 296.4 & 8.68 & \multirow{2}{*}{$1.31 @$} \\
\hline Mothers & 30 & 295.4 & 9.56 & \\
\hline
\end{tabular}

\section{@ Not Significant}

Table 3 revealed that the scores (314.1) of mothers of normal children and mean score (316.5) of fathers of normal children and its difference is very less (2.4). The obtained' value (0.39) is not significant. Hence, there is no significant difference between the fathers and mothers of normal children with regard to the attitude towards their children is accepted.

Table 3

Means and Standard Deviations of Fathers and Mothers of Normal Children and the Result of ' $t$ ' Test.

\begin{tabular}{|l|l|l|l|l|}
\hline \multicolumn{1}{|c|}{ Groups (Normal Children) } & N & Mean & S.D & 't' test \\
\hline Fathers & 30 & 313.2 & 21.53 & \multirow{2}{*}{$0.39 @$} \\
\hline Mothers & 30 & 315.3 & 22.41 & \\
\hline
\end{tabular}

@ Not Significant 
Table 4 depicts that the mean score (298.5) of mothers of hearing impaired children and the mean score (316.6) of mothers of normal children. Results indicate that the mothers of normal children had possessed better attitude towards their children than the parents of hearing impaired children. The obtained't' value (4.02) is significant. Hence, there is significant difference between the mothers of hearing impaired and mothers of normal children with regard to the attitude towards their children is rejected.

Table 4

Means and Standard Deviations of Mothers of Hearing Impaired Children and Normal Children, the Result of' $t$ ' Test.

\begin{tabular}{|l|l|l|l|l|}
\hline \multicolumn{1}{|c|}{ Groups } & $\mathrm{N}$ & Mean & S.D & 't' test \\
\hline Mothers of hearing impaired children & 30 & 297.6 & 9.75 & \multirow{2}{*}{$4.01 * *$} \\
\hline Mothers of normal children & 30 & 315.4 & 22.54 & \\
\hline
\end{tabular}

\section{** Significant at 0.01 level}

Table 5 discloses that the mean score (295.3) of fathers of hearing impaired and the mean score (315.5) of fathers of normal children. Results shows that children than the fathers of hearing impaired. The obtained ' $t$ ' value (4.36) is significant. Hence, there is significant difference between the fathers of hearing impaired and fathers of normal children with regard to the attitude towards their children is rejected.

Table 5

Means and Standard Deviations of Fathers of Hearing Impaired Children and Normal Children, the Result of't' Test.

\begin{tabular}{|l|l|l|l|l|}
\hline \multicolumn{1}{|c|}{ Groups } & N & Mean & S.D & 't' test \\
\hline Fathers of hearing impaired children & 30 & 296.2 & 8.76 & \multirow{2}{*}{$4.34 * *$} \\
\hline Fathers of normal children & 30 & 314.6 & 21.92 & \\
\hline
\end{tabular}

IV.

CONCLUSIONS

1. Parents of normal children had better attitude than the parents of hearing impaired towards their children.

2. No significant difference was observed in the fathers and mothers of hearing impaired children.

3. No significant difference was observed in the fathers and mothers of normal children.

4. Mothers of normal children had possessed better attitude than the mothers of hearing impaired children towards their children.

5. Fathers of normal children had possessed better attitude than the fathers of hearing impaired children towards their children

6. Parents of normal children had better attitude than the parents of hearing impaired towards their children.

7. No significant difference was observed in the fathers and mothers of hearing impaired children. No significant difference was observed in the fathers and mothers of normal children

\section{REFERENCES}

[1]. Daniel \& Dibwad (1977) Problems of parents towards deaf children. British Journal Educational Psychology, Vol.52 920, pp. 232-234.

[2]. Himavalli, P. (1989). Parents Attitude Towards Their Deaf Children Comparison Between Mothers and Fathers. M.Sc. Dissertation, Sri Venkateswara University, Tirupati.

[3]. Kalavathi, V (1993). Parental Attitude Towards Their Handicapped Children. Ph.D. Thesis, Sri Venkateswara University, Tirupati.

[4]. Schafer, E.S. \& Bell, R.Q. (1958). Development of a parental attitude research instrument, Child Development, Vol. 29, pp.339-361.

[5]. Shoben EJ. (1949). The assessment of parental attitude in relation to child adjustment. Genetic Psychology Monographs, 39, 101-148.

[6]. Wendel (1980). Child deafness and mother-child interaction. Child Development Journal, Vol. 51 (3), pp. 766-774. 